\title{
Evaluation of the use of the FAS endoluminal brush and $20 \%$ ethanol flushes to unblock central venous catheters used for long-term parenteral nutrition
}

\author{
W. N. Magambo ${ }^{1}$, S. Harwood ${ }^{1}$, M. O’Connell ${ }^{2}$, S. Galliford ${ }^{1}$, A. Llewellyn-Edwards ${ }^{1}$, S. Tracey ${ }^{1}$, \\ L. Hopkins ${ }^{1}$, A. L. Jukes ${ }^{1}$ and A. B. Hawthorne ${ }^{1}$ \\ ${ }^{1}$ Nutrition Support Team University Hospital of Wales, Cardiff, CF14 4XW, UK and ${ }^{2}$ Calea WA7 1NT, UK
}

Catheter occlusion is the second most common problem associated with vascular access devices ${ }^{(1)}$. In patients receiving parenteral nutrition (PN), lipid deposits can form a waxy substance along the lumen of the line which gradually occludes the central venous catheter $(\mathrm{CVC})^{(2)}$. The use of $70 \%$ ethanol locks has been reported to unblock lipid occlusions ${ }^{(3)}$; while a $20 \%$ ethanol flush after lipid infusions has been reported to help prevent the build-up of lipid deposits that occlude the $\mathrm{CVC}^{(4,5)}$.

Endoluminal brushing of CVC's is more widely known for improving flow rates in catheters used for haemodialysis ${ }^{(5,6)}$. The FAS endoluminal brush has been used successfully to diagnose CVC related sepsis, while the line remains in situ ${ }^{(7-9)}$. In this study, the FAS endoluminal brush is used to salvage occluded CVC's used for long-term PN.

A retrospective audit was done on all the patients receiving long-term PN over the preceding 4 years.

Seventy six FAS endoluminal brushes were performed on 40 patient episodes of line occlusions over a 4-year period.

\begin{tabular}{|c|c|c|c|c|c|c|}
\hline & $\begin{array}{c}\text { No. of patient } \\
\text { episodes with line } \\
\text { occlusion }\end{array}$ & $\begin{array}{l}\text { No. of } \\
\text { patients }\end{array}$ & $\begin{array}{c}\text { No. of } \\
\text { endoluminal brushes }\end{array}$ & $\begin{array}{l}\text { Successfully } \\
\text { cleared occlusions }\end{array}$ & $\begin{array}{c}\text { Unsuccessful } \\
\text { brushes requiring } \\
\text { new CVC }\end{array}$ & $\begin{array}{c}\text { Partially } \\
\text { cleared occlusions }\end{array}$ \\
\hline 2005-6 & 11 & 5 & 19 & 9 & 1 & 1 \\
\hline 2006-7 & 11 & 8 & 16 & 9 & 0 & 2 \\
\hline $2007-8$ & 11 & 7 & 26 & 8 & 2 & 1 \\
\hline 2008-9 & 7 & 6 & 15 & 3 & 3 & 1 \\
\hline Total & 40 & $16^{*}$ & 76 & 29 & 6 & 5 \\
\hline
\end{tabular}

Eighty five percent of all patient episodes had the CVC salvaged. Fourteen percent of these required a linogram post brushing to fully restore the patency of the CVCs. All the failed patient episodes had CVC occlusion caused by fibrin sheath. The mean no. of patient episodes was 2.5. One patient had a total of 7 episodes of CVC occlusions.

Prior to the introduction of the FAS endoluminal brush, the first line treatment for blocked CVCs used for PN was either urokinase lock or an ethanol lock. This has since changed to FAS endoluminal brushing followed by $20 \%$ ethanol flush (5 ml). Weekly flushing of the long-term CVCs with $20 \%$ ethanol $(5 \mathrm{ml})$ has since been introduced to maintain patency of the catheter. This has shown to be beneficial more so in the patients who had repeated CVC occlusions due to lipid deposits.

1. Haire WD, Lieberman RP, Lund GB, et al. (1990) Cancer 66, 2279-2285.

2. Baranowski L (1993) J Intraven Nurs 16, 167-194.

3. Pennington CR \& Pithie AD (1987) J Parenter Enter Nutr 11, 507-508.

4. Hardy G (2005) Curr Opin Clin Nutr Metab Care 8, 277-283.

5. Tranter S \& Donoghue J (2000) Aust Crit Care 13, 10-136.

6. Dittrner ID, Sharp D, Williams AJ et al. (1996) The use of catheter brushes to diagnose internal luminal colonization of haemodualysis catheters. Presentation at the Autumn Meeting of the Royal College of Physicians, London.

7. Dobbins BM \& Kite P (1999) Nutrition 15, 66-67.

8. Kite P, Dobbins BM, Wilcox MH et al. (1997) J Clin Pathol 50, 278.

9. Tighe MJ, Kite P, Fawley WN et al. (1996) BMJ 313, 1528. 